\title{
Adolescents as our future and the pattern of violence against women and girls: experiences of the rivers state observatory
}

\begin{abstract}
Background: Violence against women and girls (VAWG) is a growing global health concern and the culture of silence creates a negative impact on incident reporting. The Rivers State Observatory on VAWG coordinated by the Medical Women's Association of Nigeria, Rivers State branch was set up by the Nigeria Stability and Reconciliation Program to manage a virtual safe space and gather information about VAWG, its trends, prevalence and the response by state and non-state actors.
\end{abstract}

Objective: This manuscript presents the findings of an intervention on VAWG to determine the pattern of VAWG reported to the Rivers State Observatory in Port Harcourt, Nigeria.

Design: The Rivers State Observatory on VAWG established and managed a virtual safe space to conduct a prospective study of VAWG from 2015 to 2017. A standardised Incident Reporting Form was used to collect information from survivors of violence.

Results: Of 621 reported incidences, domestic violence (33.5\%), child abuse $(31.2 \%)$, other human rights violations $(13.7 \%)$ and sexual violence $(13 \%)$ were the most common. One-third of the survivors were children (33.8\%), with 55\% belonging to $11-17$ years age group and $13.2 \%$ belonging to the under-five age group. One-third of the survivors $(33 \%)$ suffered repeated/chronic violence and $116(19 \%)$ were victims of gang attacks.

Conclusion: Adolescents suffer violence and repeated attacks are rift. There is urgent need to broaden the campaign against VAWG and strengthen interventions to prevent VAWG.

Keywords: adolescents, pattern, violence against women and girls, rivers state, observatory
Volume 9 Issue 3 - 2018

\author{
Eke Gracia Ker, ${ }^{1,2}$ Agala Vetty Rolegherig,, 13 \\ Adebiyi Obelebra, ${ }^{1,4}$ Rosemary Nkem Ogu ${ }^{1,5}$ \\ 'Medical Womens Association of Nigeria, Nigeria \\ ${ }^{2}$ Department of Paediatrics and Child Health, University of Port \\ Harcourt, Nigeria \\ ${ }^{3}$ Rivers State Ministry of Health, Nigeria \\ ${ }^{4}$ Rivers State Hospitals Management Board, Nigeria \\ ${ }^{5}$ Department of Obstetrics \& Gynaecology, University of Port \\ Harcourt, Nigeria
}

Correspondence: Dr. Rosemary Nkem Ogu, Department of Obstetrics and Gynaecology, University of Port Harcourt, Rivers State, Nigeria, Tel 234-8033129937,

Email rosemary.ogu@uniport.edu.ng

Received: March 06, 2018| Published: May 23, 2018

\section{Introduction}

Violence against women and girls (VAWG) has been defined as "Any act of gender-based violence that results in, or is likely to result in, physical, sexual or psychological harm or suffering to women, including threats of such acts, coercion or arbitrary deprivation of liberty, whether occurring in public or in private life". ${ }^{1}$ Also known as gender-based violence, these acts of violence are committed against women because of their gender. This violence is a manifestation of historically unequal power relations between men and women ${ }^{1,2}(\mathrm{~A} /$ RES/48/104, Nnadi I.). It is a worldwide phenomenon that has torn into the fabric of society and become a global public health concern. ${ }^{2}$ VAWG is a grave human right violation that manifests itself in several ways, including domestic/intimate partner violence-its most common form - sexual assault, child marriage, widowhood practices, female genital cutting, and trafficking of women and girls. ${ }^{1-3}$ Violence against women is perhaps the most shameful and pervasive human rights violation.

The impact of VAWG can be immediate or long-term and includes physical, sexual and mental consequences, including death, for women and girls. ${ }^{3,4}$ VAWG negatively affects women's general wellbeing and prevents them from fully participating in society, despite their important role in the development of any nation. ${ }^{3,4}$ In addition to the lives lost and damaged, research also shows that violence has huge economic costs, including direct costs for health, legal, police and other services. ${ }^{5}$ Unfortunately, most of these cases are kept silent, despite their pervasiveness. In many cases, victims, who are also referred to as survivors, are mistreated by the law and stigmatised and dehumanised by society. ${ }^{6}$

For several decades, ending gender-based violence has remained a high national and international priority. However, despite several international agreements, among which are the Convention on the Elimination of All Forms of Discrimination against Women (CEDAW) and the United Nation Declaration on the Elimination of Violence against Women, which provided a framework for action on the pandemic, at least one in every three women worldwide continue to experience VAWG, often from the hands of those who claim to love or protect them. ${ }^{1,4,6-8}$ Additionally, it has been reported that in 2012, violence took the lives of approximately 54,000 girls between the ages of 10 and 19 worldwide, making it the second leading cause of death in this population group. ${ }^{4}$ Adolescents are our future. ${ }^{9}$ Sensitization on crimes against adolescents and children is now more than ever a necessary strategy for safeguarding our future.

Africa, the Middle East and Southeast Asia have been observed to have the highest reported rates of sexual and physical violence towards women. ${ }^{7}$ A study in Namibia revealed that cultural factors, alcohol consumption, low levels of education, lack of employment, socio-economic marginalisation, broken family systems, and poor socialisation, were all contributing factors underlying violent crimes committed against women and children. ${ }^{10}$

In Nigeria, the problem of violence against women is primarily rooted in the traditional patriarchal structure of the society. Several cases of VAWG have been reported there. ${ }^{2,7}$ However, as in many 
developing nations, despite its recognition, investment in prevention and services for survivors remain woefully inadequate. This deficiency is, to a certain extent, related to the paucity of data, especially in our environment, where a prevalent culture of silence discourages reporting.

To help address this gap and in an effort to reduce the prevalence of VAWG, the Nigeria Stability and Reconciliation Programme (NSRP), along with other groups, supported the establishment of virtual safe spaces in the form of observatories as a repository of information on VAWG in the 8 states, including Rivers State, most affected by violent conflict. ${ }^{11}$

Therefore, this study was conducted to determine the pattern of VAWG reported to the Rivers State Observatory in Port Harcourt, Nigeria.

\section{Methodology}

This prospective study was carried out in Port Harcourt, the capital of Rivers State, which is located in the Niger Delta region of Nigeria. According to the 2006 population census, Rivers State has approximately 5,198,716 residents; $48.5 \%$ female, and approximately $70 \%$ rural dwellers. Rivers State is the heart of the hydro-carbon industry, which is responsible for a large part of the nation's foreign exchange earnings. ${ }^{12}$ This state is also one of the most violent in the Niger Delta region. In the last several years, Rivers State has experienced high levels of violence from militancy, criminality, cults and political rivalry.

The study population was a convenient sample of all survivors of VAWG whose cases were reported at the Rivers State Observatory from February 2015 to January 2017 as part of a 30-month project supported by the NSRP. This project was part of the NSRP's fiveyear programme aimed at supporting the initiatives of Nigerian actors and institutions to manage conflicts non-violently and reduce the impact of violent conflict on the most vulnerable population. The programme supported interventions at the federal level but focused more on 8 states, including Rivers State, in 4 zones most affected by violent conflict in Nigeria. Specifically, these zones are the Northeast, Northwest, Middle Belt and Niger Delta. ${ }^{13}$ The programme also supported the establishment of virtual safe spaces in the form of observatories as a repository of information to improve state and nonstate reporting, referral and response on VAWG.

The Rivers State Observatory was coordinated by the Medical Women's Association of Nigeria (MWAN) - Rivers State Branch and steered by a committee of representatives of relevant state actors, security agencies and non-state actors, including Civil Society Organisations (CSO), Community-based organisations (CBO) and religious groups who partnered with the NSRP in its initiative to reduce VAWG. Reporting, referral and response to incidents of VAWG were performed through these institutions and organisations, as well as the general public using a standardised incident reporting form. Information obtained included biographical data, the type of violence, characteristics of the perpetrators and a description of the incident.

The Observatory Steering Committee (OBSTEC) connected survivors to available services and ensured responsive action when consent was granted.

Permission for the study was obtained from the Regional Office of NSRP in Port Harcourt. Data were entered into a Microsoft Excel spreadsheet and analysed using SPSS 20.0. P values $<0.05$ were considered to be significant. The results are presented using tables and charts.

\section{Results}

A total of 621 incidences were reported in the period under review. Survivors were all female, and 211 (34\%) were children. Among these survivors, more than half (55\%) belonged to the 11-17years age group, while $28(13.2 \%)$ belonged to the $0-5$ years' age group Table 1 shows the age group, number and percentage of all survivors.

Table I Ages of Survivors

\begin{tabular}{lll}
\hline Age group of survivors & Frequency & Percentage \\
\hline $0-5$ years & 28 & 4.5 \\
6-10 years & 67 & 10.8 \\
II-I7 years & 116 & 18.7 \\
I8-30 years & 63 & 10 \\
$31-40$ years & 14 & 2.3 \\
$>40$ years & 17 & 2.7 \\
Adults (Age Unspecified) & 316 & 51 \\
Total & $\mathbf{6 2 I}$ & 100 \\
\hline
\end{tabular}

The ages of most of the adults were unspecified.

The most common types of VAWG reported were domestic violence $(33.5 \%)$ followed by child abuse $(31.2 \%)-80 \%$ of which were cases of defilement, including incest, human rights violations $(13.7 \%)$ and sexual violence (13\%). Twenty-five survivors (4\%) were victims of gang violence, including a survivor with a disability who was gang raped (Table 2).

Table 2 Types of Incidents Reported

\begin{tabular}{|c|c|c|}
\hline Indicators & Frequency & Percentage \\
\hline Domestic violence & 208 & 33.5 \\
\hline $\begin{array}{l}\text { Child abuse: defilement, flogging, excessive } \\
\text { chores }\end{array}$ & 194 & 31.2 \\
\hline $\begin{array}{l}\text { Human rights violations: physical violence, } \\
\text { denial of inheritance, stigma towards single } \\
\text { ladies, employment discrimination }\end{array}$ & & 13.7 \\
\hline Sexual violence & 80 & 13 \\
\hline Gang violence & 25 & 4 \\
\hline Abduction & 14 & 2.2 \\
\hline Abuse by public security forces & 8 & 1.3 \\
\hline Harmful traditional practices & 5 & 0.8 \\
\hline Health issues & 2 & 0.3 \\
\hline Total & 621 & 100 \\
\hline
\end{tabular}

The majority 294 (48\%) of violent incidents were committed by a single offender, and $116(19 \%)$ cases were committed by multiple offenders. One-third of cases were the result of chronic abuse (Figure 1).

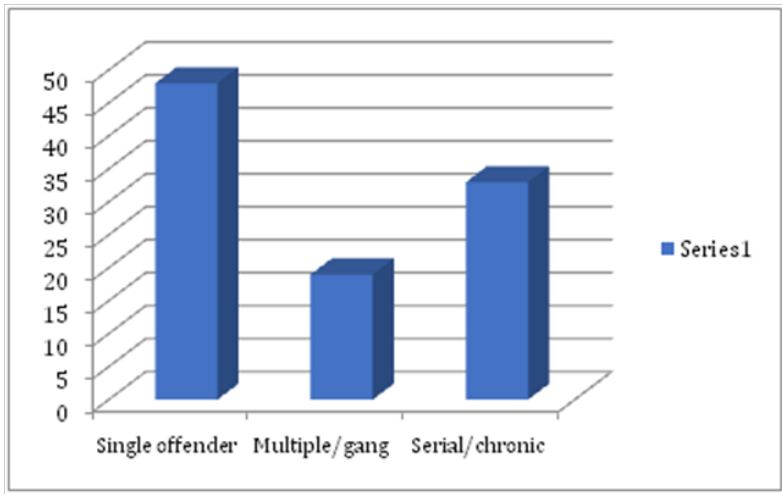

Figure I Characteristics of the incidents. 
The ages of the majority of offenders (88.6\%) were not specified. Among those with specified ages, the age group of 30-39 years was most prevalent $(4 \%)$, and there were no offenders younger than 10 years of age. Spouses and partners constituted the largest group of perpetrators $(29.3 \%)$ of VAWG followed by neighbours and friends $(21.6 \%)$. Overall, $473(76.2 \%)$ offenders were people whom the survivors knew, and $115(18.5 \%)$ of incidents of violence were perpetrated by individuals' unknown to the survivors (Table 3 ).

Table 3 Characteristics of Perpetrators ofVAWG

\begin{tabular}{lll}
\hline Age of perpetrators & Frequency & Percentage \\
\hline 0-9 years & 0 & 0 \\
I0-19 years & 12 & 2 \\
20-29 years & 13 & 2.1 \\
$30-39$ years & 25 & 4 \\
$40-49$ years & 10 & 1.6 \\
$\geq 50$ years & 11 & 1.7 \\
Unspecified & 550 & 88.6 \\
Identity/relationship with survivor & & \\
Spouse/partner & 182 & 29.3 \\
Neighbour/friend & 134 & 21.6 \\
Relation (father, brother, cousin, uncle/aunt) & 66 & 10.6 \\
Guardian & 34 & 5.5 \\
Colleague & 25 & 4 \\
Cultist & 12 & 2 \\
Security official & 10 & 1.6 \\
Political thug & 2 & 0.3 \\
Employer & 5 & 0.8 \\
Teacher & 3 & 0.5 \\
Unknown (including public transport driver, & 115 & 18.5 \\
robbers and cultists) & 33 & 5.3 \\
Not mentioned & 62 I & 100 \\
Total & & \\
\hline
\end{tabular}

In $90 \%$ of cases, perpetrators of violence were males. Offenders were female in 53 cases (8\%) (Figure 2).

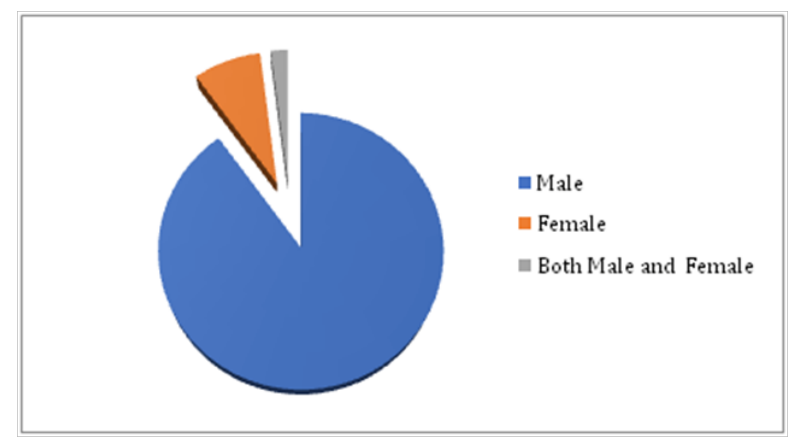

Figure 2 Gender of perpetrators ofVAWG.

\section{Discussion}

Acts of violence against women and girls are human rights violations and occur in all countries, social groups and age groups. In this series, children constituted $34 \%$ of survivors, which is lower than the $56 \%$ obtained in Benin City, $83 \%$ in Lagos and $91 \%$ in Jigawa, Northwest Nigeria. ${ }^{7,14,15}$ The disparity may be attributed to the study methodology because these previous reports were all hospital-based and focussed on sexual assault. Sexual assault was one of several aspects of VAWG considered in the present report. Childhood survivors of violence is worrisome because early childhood experiences of violence has been associated with a higher likelihood of suffering from behavioural and emotional disturbances, as well as perpetrating or experiencing violence later in life..$^{5,14}$

Survivors with disabilities represented $0.2 \%$ of this study population. This value is in agreement with previous reports and suggests that underreporting of violence is worse among women with disabilities. This finding may be observed because women with disabilities have additional complicating factors that can prevent them from reporting abuse. ${ }^{16-18}$ One factor is the high dependency on caregivers for affection, communication, financial assistance and physical support. ${ }^{16}$ Moreover, when the abuser is a family member or someone responsible for her, access to justice is often denied..$^{18}$ Thus, despite several international studies showing that women with disabilities are twice as likely to experience gender-based violence as women who do not have a disability, the violence that they experience remains largely invisible.

While reports reveal that domestic violence is the most common violence experienced by women and girls in Nigeria, there is gross underreporting and improper documentation of its incidence. This form of abuse is perpetrated in the family or home by a husband, boyfriend, brother or other relative. It was the most common form of VAWG reported in this series and accounted for 33\% of cases. This figure is comparable to that obtained by the CLEEN Foundation's nationwide survey, in which 1 in every 3 respondents admitted to being a victim of domestic violence. Another survey identified drunkenness, financial issues, and the rejection of a partner's sexual advances as the main causative factors. ${ }^{19,20}$ Even though causes of domestic violence were not explored in this study, the patriarchal system, which predominates in our society, is generally considered a strong contributor. VAWG within the home, including excessive chores, which alone is not regarded as violence, is seen as a tool to punish and train women and girls. ${ }^{20,21}$ Unfortunately, this traditional belief is socially acceptable in our environment. Therefore, the culture of silence prevails, while abuse is effectively ignored by the state and the law enforcement machinery.

Sexual violence, also refer to as sexual assault or sexual abuse, is not unique to any race or socio-economic class; Nigerian women and girls are confronted with it daily. The majority of the cases reported are attempted rape or rape in adults and children. In this study, $13.7 \%$ of subjects reported sexual violence. This figure is comparable to the $13.8 \%$ reported in the study involving female students in Maiduguri but higher than prevalence of rape from facility-based studies. ${ }^{15,22,23}$ This reiterates the fact most cases of sexual assault are underreported to health facilities by the victims because of the associated stigma.

Defilement, including incest, is defined as any sexual relationship between an adult and any child placed under his care by birth or upbringing. Defilement accounted for $25 \%$ of all reported cases and $80 \%$ of cases of child abuse. It is noteworthy that among these children, adolescents experienced the higher rate of sexual assault than any other age group, a finding consistent with previous reports. ${ }^{7,14}$ Although this group of young people has been the target of much gender-based violence, the fear of unwanted pregnancy may account for more adolescent girls presenting to healthcare facilities than premenarchal children. ${ }^{7,14,24}$ There is thus a need for programmes that specifically assist this vulnerable group. These programmes should include age-appropriate sexual assault education with life skills training for protection. Such programmes will not only help in reducing the risks of violence but also improve chances that an assault will be reported when it occurs. Implementing youth-friendly health services in schools and communities may assist in enabling 
reporting; the odds of youths utilizing health facilities increased when the services are youth friendly. ${ }^{25}$

In this study, $76.2 \%$ of perpetrators were known or trusted by the survivor or the survivor's family. This finding is truly traumatic and impacts the willingness of survivors to report an incident. Not reporting these incidents can have grave implications because the abuse may become chronic and more severe before being detected. Additionally, abuse of trust by family and community figures highlights harmful norms which contribute to VAWG in our society. There is thus an urgent need for sensitization to broaden the campaign against VAWG and strengthen interventions to prevent VAWG.

The limitation of this study was that incident reports were primarily submitted through the representative organisation that first interviewed the survivor. This limitation, however, did not diminish the importance of the events.

\section{Conclusion}

VAWG is common in Rivers State. Several different types of violence are experienced, and trust is often abused, leaving women and girls vulnerable. Children, especially adolescents, constituted a large proportion of the survivors. Perpetrators of violence were mostly nonstrangers. There is a need for all stakeholders to broaden the campaign against this evil. Standardisation of reporting and responding and improved interventions is necessary to break this pervasive culture of silence and prevent VAWG.

\section{Acknowledgements}

We thank the Nigerian Stability and Reconciliation Programme (NSRP) for the technical support and monitoring of the Medical Women's Association of Nigeria MWAN Observatory (British Council NSRP Grant No 718005).

We thank Dr. Eleanor Nwadinobi, Mrs. Ineba Bob-Manuel and our other partners. We also thank the state and non-state actors who are first responders to violence against women and girls in Rivers State. Special appreciation goes to the Deputy Governor of Rivers State, Dame Dr. Ipalibo Harry Banigo for her passion through the "Protect the Girl Child" campaign.

Many thanks to the Medical Women's Association of Nigeria for providing the platform for the implementation of this project. The survivors who spoke out are highly appreciated.

\section{Conflicts of interest}

The authors declare that they do not have any conflicts of interest.

\section{References}

1. United Nations. Declaration on the Elimination of Violence against Women. 1993.

2. Nnadi I. An Insight into Violence against Women as Human Rights Violation in Nigeria: A Critique. J Polit Law. 2012;5(3):48.

3. Noah Y. Incidence and dimension of violence against women in the Nigerian society: A case study of Ilorin Township. Centrepoint Univ Ilorin Niger. 2001;10(1):65-76.

4. UNICEF Division of Data. A statistical snapshot of violence against adolescents girls. New York: United nations children's fund; 2014.
5. Garcia-Moreno C, Watts C. WHO Violence against women: an urgent public health priority. Bull World Health Organ. 2011;89(1):2.

6. Kelly L. Surviving Sexual Violence (Feminist Perspectives). 1998.

7. Akinlusi FM, Rabiu KA, Olawepo TA, et al. Sexual assault in Lagos, Nigeria: a five year retrospective review. BMC Womens Health. 2014; $14: 115$.

8. UN General Assembly. Convention on the Elimination of All Forms of Discrimination against Women CEDAW. New York: ISN ETH Zurich; 1979.

9. Patton GC, Sawyer SM, Santelli JS, et al. Our future: a Lancet commission on adolescent health and wellbeing. The Lancet. 2016;387(10036):2423-78.

10. Ministry of Safety and Security. Understanding the perpetrators of violent crimes against women and girls in Namibia: Implications for prevention and treatment. A research project supported by BristolMyer Squibb Foundation and Konrad-Adenauer-Stiftung, Namibia: University of Namibia; 2006.

11. The Fund for Peace. Nigeria Stability and Reconciliation Programme. Rivers State: Medical Women's Association of Nigeria; 2016.

12. Federal Republic of Nigeria Official Gazette. Legal Notice on Publication of 2006 Census Final Results. 2006;96:39-40.

13. NSRP. Nigeria Stability and Reconciliation Programme. 2015.

14. Akhiwu W, Umanah I, Olueddo A. Sexual Assaults in Benin City, Nigeria. TAF Prev Med Bull. 2013;12(4):377-82.

15. Ashimi A, Amole T, Ugwa E. Reported Sexual Violence among Women and Children Seen at the Gynecological Emergency Unit of a Rural Tertiary Health Facility, Northwest Nigeria. Ann Med Health Sci Res. 2015;5(1):26-9.

16. Naidu E, Haffejee S, Vetten L, et al. On the margins: Violence against women with disabilities. 2005.

17. Ortelova S, Lewis H. Forgotten Sisters - A report on violence against women with disabilities. An overview of its nature, scope, causes and consequences. 2012 .

18. Southern Africa Litigation Centre. Prosecuting sexual violence against women and girls with disabilities in Malawi: A preliminary analysis of the attrition of sexual offence cases in the criminal justice system. 2017.

19. CLEEN Foundation. National Crime Victimization Survey. 2013.

20. Project Alert. Sexual Violence in Nigeria: A Silent Epidemic. 2017.

21. Uthman OA, Lawoko S, Moradi T. Factors associated with attitudes towards intimate partner violence against women: a comparative analysis of 17 sub-Saharan countries. BMC Int Health Hum Rights. 2009;9:14.

22. Kullima AA, Kawuwa MB, Audu BM, et al. Sexual assault against female Nigerian students. Afr J Reprod Health. 2010;14(3):189-93.

23. Olowookere SA, Fawole OI, Adekanle DA, et al. Patterns and Correlates of Intimate Partner Violence to Women Living With HIV/ AIDS in Osogbo, Southwest Nigeria. Violence Against Women. 2015;21(11):1330-40.

24. Eke GK, Opara PI, Akani NA. Mothers' knowledge and perception of child sexual abuse. P H Med J. 2010;4(3).

25. Ogu R, Maduka O, Alamina F, et al. Mainstreaming youth-friendly health services into existing primary health care facilities: experiences from South-South Nigeria. Int J Adolesc Med Health. 2018. 